\title{
Unequally vulnerable: a food justice approach to racial disparities in COVID-19 cases
}

\author{
Alison Hope Alkon ${ }^{1} \cdot$ Sarah Bowen $^{2} \cdot$ Yuki Kato $^{3} \cdot$ Kara Alexis Young ${ }^{4}$
}

Accepted: 27 April 2020 / Published online: 20 May 2020

○) Springer Nature B.V. 2020

Although some have called COVID-19 "the great equalizer," recent data from the CDC shows that Black, Latinx and Native American people become infected and die more often than whites ${ }^{1}$. In a recent press briefing NIAID Director Dr. Anthony Fauci described these disparities in terms of the prevalence of "underlying medical conditions-the diabetes, the hypertension, the obesity" (quoted in Lahut 2020).

While few would contend that diet is the only or even the main cause of these disparities, some medical experts, including Dr. Fauci, argue that Americans' diet-related health conditions make us uniquely and unequally vulnerable. We can interrogate this claim using a food justice perspective, which examines how racial capitalism affects the production, distribution and consumption of food.

Popular culture and nutrition science tend to conceptualize diet as the result of individual choices. In contrast, food justice researchers emphasize the structural conditions that affect food consumption. A food justice framework argues that food is more than just calories and grocery stores. Residential segregation and gentrification, racism in public health and medical institutions and labor conditions throughout the food sector contribute to racial and economic foodrelated health disparities.

As food justice researchers, we argue that dietary decisions are often constrained by spatial and economic disparities in access to healthy food. These disparities are rooted in racist urban development policies like redlining and urban renewal, which have long left communities of color without

This article is part of the Topical Collection: Agriculture, Food \& Covid-19.

\footnotetext{
Alison Hope Alkon

aalkon@PACIFIC.EDU

University of the Pacific, Stockton, CA, USA

North Carolina State University, Raleigh, NC, USA

George Washington University, Washington, DC, USA

The Ohio State University, Columbus, OH, USA
}

the means to invest in their built environments while targeting them for demolition through eminent domain. Efforts to "green" these neighborhoods by bringing in health stores and urban farms can increase property values and displace low-income people and people of color to areas with even more limited food access.

Moreover, the growing gap in the diets of rich and poor people goes beyond physical access to supermarkets. Foods that are often touted as healthy are expensive, and many lowincome families simply are forced to do without them. Food justice research also documents racism in food stores and in consulting with nutrition and health professionals. Additionally, the cultural whiteness of public health campaigns and alternative food movements can inadvertently exclude these communities.

Beyond diet disparities, labor conditions throughout the food industry predispose people of color to a variety of health risks. Black and Latinx workers are over-represented in the lowest-wage sectors of the food industry. Many of these workers are deemed "essential" and continue to risk their lives to keep the food system functioning. Major supermarket chains have reported employee deaths, and the soaring rates of infection in meatpacking plants reveals a rampant, industry-wide disregard for the safety of their workforces. People of color are also likely over-represented among Amazon warehouse and food delivery workers, who have had to strike for paid sick leave, sanitization procedures, and basic protections like hand sanitizer. As middleclass consumers' reliance on these services increases, those who perform this "essential" work remain unprotected physically, socially, and financially, contributing to elevated infection and mortality rates.

In the press conference described at the beginning of this commentary, Dr. Fauci remarked that the current crisis shines a bright light on how unacceptable these health

\footnotetext{
${ }_{1}^{1}$ In some areas such as NY city, Asian communities also experience elevated infection and mortality rates.
} 
disparities are. As food justice scholars have long shown, food insecurity and workplace exploitation are disproportionately experienced by low-income people and people of color not because of poor choices, but because of structural racism and economic inequalities (Laster Pirtle 2020). Now, in the time of this pandemic, we are seeing that we do not have a strong social safety net to assist the large number of food-insecure households, nor do we have work protections to ensure that our lowest paid workers can make it through this crisis safely.

Unfortunately, it is Black, Latinx, and Indigenous communities that these failures hit the hardest as they unequally bear the burden of risk and illness. While stark racial health disparities predate COVID-19, if we continue to turn a blind eye to the classism and racism embedded within our food system, these disparities will inevitably widen as this pandemic weaves its way through the population.

\section{References}

Lahut, J. 2020. Faucci says the coronavirus is 'shining a bright light' on 'unacceptable' health disparities for African Americans. Business Insider. https://www.businessinsider.com/fauci-covid-19-shows -unacceptable-disparities-for-african-americans-2020-4

Laster Pirtle, W. 2020. Racial capitalism: A fundamental cause of novel coronavirus (COVID-19) pandemic inequities in the United States.
Health Education and Behavior. https://doi.org/10.1177/10901 98120922942.

Publisher's Note Springer Nature remains neutral with regard to jurisdictional claims in published maps and institutional affiliations.

Alison Hope Alkon is Professor of sociology at The University of the Pacific. She is the author of Black White and Green: Farmers Markets, Race and the Green Economy and co-editor of A Recipe For Gentrification: Food, Power and Resistance in the City and Cultivating Food Justice: Race, Class and Sustainability.

Sarah Bowen is Associate Professor of Sociology at North Carolina State University. She is the author of Divided Spirits: Tequila, Mezcal, and the Politics of Production and co-author of Pressure Cooker: Why Home Cooking Won't Solve Our Problems and What We Can Do About It.

Yuki Kato is Assistant Professor of Sociology at George Washington University and a Food Justice Fellow at the Center for Social Justice. She is co-editor of A Recipe For Gentrification: Food, Power and Resistance in the City and Cultivating Food Justice: Race, Class and Sustainability and is currently writing a manuscript entitled Cultivating the City: Urban Agriculture in Post-Katrina New Orleans.

Kara Alexis Young is Assistant Professor of sociology at The Ohio State University and the Food Disparities Expert for The Initiative for Food and AgriCultural Transformations (InFACT) Discovery Theme. Her book project, Gut Feelings: Emotions, Social Status and Food Inequality in the American City is currently under review. 